\title{
An investigation of discourse cohesion in Indian male-female causal narration
}

\author{
Nagaraj, Hema $\bowtie$ \\ All India Institute of Speech and Hearing,University of Mysore, India (hema_chari2@yahoo.com) \\ Singh, Nidhi \\ All India Institute of Speech and Hearing, University of Mysore, India (nidhisingh.nidz@gmail.com) \\ Ponnuchamy, Vishali \\ All India Institute of Speech and Hearing, University of Mysore, India (vishalikrish8@gmail.com)
}

Thotathil, Jijina

All India Institute of Speech and Hearing, University of Mysore, India (jijina.rocks@gmail.com)

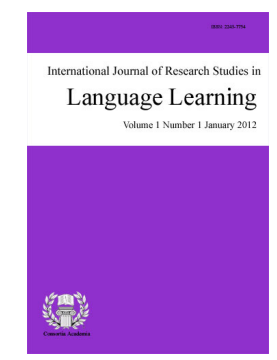

ISSN: 2243-7754

Online ISSN: 2243-7762

OPEN ACCESS

$\begin{array}{lll}\text { Received: } 2 \text { March } 2016 & \text { Revised: } 30 \text { May } 2016 & \text { Accepted: } 10 \text { July } 2016 \\ \text { Available Online: } 17 \text { August } 2016 & \text { DOI: } 10.5861 / \text { ijrsll.2016.1481 } & \end{array}$

\begin{abstract}
Over the recent decades, the role of gender in discourse has been an intriguing arena of investigation in sociolinguistics, pragmatics and discourse analysis. Phonological, grammatical and semantic features have been pointed out that male and female discourse can be identified by a number of researchers. Significant differences in English language between male and female appear on grammatical and syntactical level, where men's discourse is asserted to be more direct and less hedged than women's discourse (Key, 1975). It is argued that women use features such as reduplicated forms, intensifiers, modal constructions and tag questions more regularly than men. While using vocabulary, women are asserted to employ different emotionally colored and vigorous adjectives, whilst men use forms that highlight masculinity, for instance barbed, bristly, and lusty, etc. The present study seeks to propose and assess parameters for investigating narrative discourse difference in cross-gender interactions between Indian male/female speakers. The parameter focused are the discourse cohesion under macro-proposition, presence or absence of transitional elements, total number of words and total time taken under micro-proposition of oral narrative discourse on a topic "profession". The quantitative approach of T-unit analysis was used to extract these parameters of narrative discourse. The data was statistically analyzed and results indicated no significant difference between the male and female participants' productivity and efficiency of discourse coherence. But there exist an increased word counts and duration taken to complete the narrative discourse by female participants compared to male participants. This could be because of the poor working memory capacity in females, requiring more words and time to narrate on a topic compared to male participants.
\end{abstract}

Keywords: discourse cohesion; T-unit analysis; macro-proposition; micro-proposition; pragmatics 


\section{An investigation of discourse cohesion in Indian male-female causal narration}

\section{Introduction}

Various discourse types and their measures have been extensively researched. In majority of researches previously conducted, the performance of neuro-typical individuals is always a reference to compare persons with communication disorders. Thus, not much emphasis has been given to discourse patterns of neuro-typical individuals. Developing an understanding of how neuro-typical individuals discourse changes with the difference in gender is imperative to effectively use discourse analysis in order to measure and to guide the treatment of disordered discourse.

Gender is one variable among the list of various variables like age, education, socio-economic status, culture, language exposure (mono/bi/multi-lingual), profession, world knowledge etc affects discourse of any neuro-typical individual. Since gender move cautiously in our day-to-day life that we consider it for granted and acknowledge it as a natural part of our lives and which needs no explanation. In our social life it manifest as any subtle and trivial aspect. In any aspect of individuals' life, this trace of gender with respect to the discourse could be found in our way of speaking, conflict, humour and so on. Language at discourse level is considered as a fruitful resource for the manifestation of gender.

In the past couple of decades, the discourse studies on the difference between male/female linguistic behaviours have increased dramatically. The scope of these studies covers variety of subjects, to name a few: the frequency of tag questions (Lakoff, 1975), the use of minimal responses in male/female discourse (Maltz \& Broker, 1982), the frequency of interruptions (West \& Zimmerman, 1983, 1987), the type of discourse markers (Ostman, 1983; Erman, 1987), the politeness strategies used by each gender (Holmes, 1995), the amount of speech delivered by each gender (Brizendine, 2006; Mehl, Vazire, Ramirez-Esparza, Slatcher, \& Pennebaker, 2007), the density of lexical in discourse (LD) verse the discourse length between male and female participants has been of great interest for scholars (Alami, Sabbah, \& Iranmanesh, 2013) and so on.

Thus, the gender role in discourse has been a rather admired field of investigation in sociolinguistics, discourse analysis and pragmatics over the recent decades. In the field of gender and language, gender identity and discourse analysis is a new collection of work by researchers. This exemplifies how an approach in terms of discourse, to the study of gender and language can ease the study of the complex and frequent subtle methods in which gender identities are embodied, constructed and challenged through language.

Investigators have scrutinized two realms of language behaviour in particular: speech behaviour of both genders on the phonological level, and in discourse (conversational styles), the interactions between them. According to Eckert and McConnell-Ginet (1992), 'women's language reflects their prestige consciousness, conservatism, upward mobility, deference, emotional expressivity, insecurity, nurturance, solidarity, connectedness and sensitivity to others. Whereas men's language is evinces their toughness, competitiveness, lack of affect, hierarchy, independence, control and competence. Likewise, the cohesion analysis of discourse has been of great interest for scholars. With this, let us introduce the concept of cohesion analysis of discourse.

According to Halliday and Hasan (1976) cohesion is defined as a structural coherence among parts of a text. Where the sentences are bounded by diverse kinds of meaning relations and this is illustrated as cohesive ties. There is a variation seen among the kinds of ties, that depend on the nature of text (i.e., communicative function), as well as the ability and style of the speaker. Relative frequency of a speaker's use of a range of categories of cohesive ties is termed as cohesive style (Liles, Coelho, Duffy, \& Zalagens, 1989). Speakers normally tend to shift their cohesive usage patterns across types of discourse and also, they may alter cohesive use in responses to variations in the context (in which the text is being created). Cohesion analyses have been useful in the characterization of individuals' language-behaviour in narrative context. 
An investigation of discourse cohesion in Indian male-female causal narration

In the recent studies, the impacts of the length of discourse samples and mode of expression on discourse measures have been investigated (Wilson \& Proctor, 2000; Wilson et al., 2001). Results have suggested that patterns of discourse such as productivity, coherence ratings and efficiency could vary with sample length and the mode of expression being conversation, narration and picture description. The assessment follows a qualitative and quantitative procedure which evaluates the ability of organizing content in any verbal narration (Coelho, Liles, \& Duffy, 1991, 1995). The current study was devised with the purpose to investigate the patterns for coherence of productivity and efficiency of narrative discourse of neuro-typical individuals on narration task in English language using a quantitative procedure.

In several studies on cohesion analysis, the quantitative procedure involved is the use of T-unit analysis. According to Hunt $(1965,1970)$, a T-unit is a "minimal terminal unit" that consists of one main clause and a subordinate clause/s or nonclausal structure/s attached to or entrenched in the main clause. Others have labelled this measure as "communication unit" (Loban, 1976). The purpose is to segment passages of continuous language into the shortest unit that is grammatically allowed to be punctuated as a sentence. Use of any smaller unit would result in fragments that would lack any independent grammatical form. If one uses the T-unit structure consistently, problems in determining when an utterance begins and ends are virtually eliminated. The analysis will provide some general indices of syntactic complexity in terms of productivity and efficiency. In addition, the clinician will be able to use the T-unit as a universal measurement base for various other analyses (Example: Word per T-unit, verbal disruptions per T-unit). An attempt is made to see the application of this procedure allowing no significant or significant differences between male and female neuro-typical individuals' narrative discourse on a topic "profession".

\section{Method}

Twenty neuro-typical individuals between the age range of 20-30 years with Mysuru cultural background (born and brought up in Mysuru) were chosen as participants for the present study. Among them, ten male participants constituted to be in Group A and the ten female participants constituted to be in Group B. The inclusionary criteria for the study included: At least 10 years of formal education in English and their second language was English for all the participants. All the participants belonged to middle or high socio-economic status as per the National Institute of Mental Health (NIMH) Socioeconomic status scale, Venkateshan (2009). Every individual who is right-handed with no alcohol/drug abuse only was considered for this study. These participants from the two groups were free from any neurological or psychological illness as determined by General Health Questionnaire (Goldberg \& Williams, 1988). The purpose and procedure of the study were explained to the participants and an informed written consent was obtained for the participation in the present study. Group A participants were matched for age, gender, education, socio-economic status of Group B.

\subsection{Procedure}

The experimental task in this study was to narrate on a topic "Profession" to the investigator (Speech-Language Pathologist) in a quiet room without any distraction during or in between the recording. In this semi-structured narration task, each participant was instructed to give as much information as possible on this particular topic within a considerable desired duration. The participants' samples were listed for individual appointments in order to complete the task of oral narration. There was a time restriction of about 8 to 10 minutes for the completion of task. The oral narration task was video recorded first and then followed a verbatim transcription of recording samples transcribed by the researcher who reassessed the sample for quantitative analysis. Thus the narrative discourse samples were transcribed and analyzed for productivity that is number of thematic unit (T-unit) (Appendix A) (an independent clause with the dependent clauses) at two levels. These are the transitional elements at local levels of coherence and the macro-proposition at global levels of coherence (Appendix B). The efficiency was evaluated in terms of the average number of words per T-unit with reference to global coherence and the total time taken to complete the narrative task (Appendix B). 


\section{Results}

There were three judges including the researcher who participated for the quantitative rating of the discourse samples. The judges were a speech language pathologist and a clinical linguist. These two judges re-checked for correct transcription and re-divided for T-unit based analysis for all the $100 \%$ of the samples. The quantitative ratings obtained from these two judges and the researcher was subjected to inter judge reliability tests using Cronbach's Alpha Reliability tests. The reliability measures for the parameters related to T-unit based analysis of narration tasks showed $>0.7$ scores suggesting that the data was reliable. Hence for further statistical analysis of this quantitative data the average of the judges was considered.

Regarding the skewness and kurtosis, the data of the present study does not differ significantly from normality even though there is a little skewness and kurtosis for both male and females. It can be assumed that the data of the present study are approximately normally distributed in terms of skewness and kurtosis. A Shapiro-Wilk's test $(p>0.05)$ (Shapiro \& Wilk, 1965; Razali \& Wah, 2011) and a visual inspection of their histograms, normal Q-Q plots and box plots showed that the values of the discourse parameters were approximately normally distributed for both males and females, with the significance value for the male participants being $0.279,0.266,0.09(p>0.05)$ and female participants being $0.252,0.727,0.519(p>0.05)$ for the parameter 'total time in seconds', 'total number of words' and 'number of transitional elements' respectively. Whereas, for the parameter 'macro proposition' the significance value for male and female participants was 0.012 and $0.035(p<0.05)$ suggesting data being not distributed normally. Hence the statistical analysis was done in two sessions. Session I- Application of parametric test to study the difference between male and female participants discourse parameters (total time in seconds, total number of words and number of transitional elements). Session II- Application of non-parametric test to study the difference between male and female participants discourse parameter called macro-proposition.

Statistical Package for the Social Sciences Version 18 software (SPSS- PASW) was used to carry out these statistical analyses in two sessions and the inter judge reliability. Initially the mean and standard deviation for coherence of productivity and efficiency of narrative discourse of neuro-typical individuals on narration task in Kannada language was calculated using descriptive statistics. The same is represented in Table 1. The mean was higher for the parameter 'number of transitional element' and total time in seconds for male participants in comparison with female participants. With respect to the parameter 'number of macro-propositions' and 'total number of words', the female participants have higher mean compared to male participants.

\section{Table 1}

Mean, Median, \& SD for coherence of productivity and efficiency of narration task for neuro-typical individuals

\begin{tabular}{lllccc}
\hline \multicolumn{1}{c}{ Parameters } & Gender & $n$ & Mean & Median & $S D$ \\
\hline Number of Transitional & Male & 10 & 5.70 & 5.00 & 2.31 \\
Element & Female & 10 & 5.60 & 6.00 & 2.06 \\
& Total & 20 & 5.65 & 5.50 & 2.13 \\
\hline Number of & Male & 10 & 3.80 & 4.00 & 0.63 \\
Macro-propositions & Female & 10 & 4.00 & 4.00 & 0.81 \\
& Total & 20 & 3.90 & 4.00 & 0.71 \\
\hline Total Number of words & Male & 10 & 263.40 & 276.00 & 52.48 \\
& Female & 10 & 287.40 & 292.00 & 87.80 \\
& Total & 20 & 275.40 & 286.00 & 71.47 \\
\hline Total Time in seconds & Male & 10 & 138.00 & 141.00 & 14.59 \\
& Female & 10 & 129.70 & 129.50 & 17.94 \\
& Total & 20 & 133.85 & 130.50 & 16.47 \\
\hline
\end{tabular}

Note: $\mathrm{n}$ - number of participants

With respect to mean, there exists a difference in the discourse parameter of male and female participants. The further statistical analysis for studying the significant difference in narrative discourse sample between the male and female participants within a group of neuro-typical individuals, Independent $t$ test was administered in 
An investigation of discourse cohesion in Indian male-female causal narration

Session I and Mann-Whitney U test was administered in Session II.

Session I (Parametric test)- There was no significant difference $(p>0.05)$ between the genders for the parameter total time taken in seconds, total number of words under the efficiency of narrative discourse and number of transitional element under the productivity of narrative discourse as shown in Table 2.

Table 2

Results of Independent t-test for the coherence of productivity and efficiency of narrative discourse of neuro-typical individuals (20-30 years)

\begin{tabular}{llcc}
\hline \multicolumn{1}{c}{ Parameters } & $t$ value & df & $p$ value \\
Group A (Male) verses Group B (Female) & & 18 & 0.271 \\
\hline Total Time in seconds & 1.135 & 18 & 0.468 \\
Total Number of words & 0.742 & 18 & 0.920 \\
Number of Transitional Element & 0.102 & \\
\hline
\end{tabular}

Note: $\mathrm{t}$ - t-test value, df- degree of freedom

Session II (Non-parametric) - There was no significant difference $(p>0.05)$ between the genders for the parameter macro-proposition, the global coherence of productivity of narrative discourse as shown in Table 3 .

Table 3

Results of Mann-Whitney Test for the coherence of productivity of narrative discourse of neuro-typical individuals (20-30 years)

\begin{tabular}{lccc}
\hline \multicolumn{1}{c}{ Parameters } & Mann-Whitney U & Z & $p$ value \\
Group A (Male) verses Group B (Female) & & & \\
\hline Number of Macro-propositions & 43.000 & 0.577 & 0.564 \\
\hline
\end{tabular}

\section{Discussion}

The whole purpose of this study was to investigate the patterns of discourse in neuro-typical individuals employing measures of coherence in terms of productivity and efficiency of narrative discourse. With reference to these measurements, comparisons were made between the male and female participants.

From the results of descriptive statistics, it is observed that the male participants used relatively more number of transitional elements with increased duration. The female participants used more number of macro-propositions and higher number of words during their narration. The reason for this is that women use figurative language whereas men keep it simple. Men speak to the point whereas women speech is marked by additional information. Women use more intense vocabulary, general questions, tag questions and hedges. Their speech is polite and lack dominance. Men's speech on the contrary contains imperatives and competitive behaviour. Women use standard language and men use dialect greatly and talk colloquially. Sentence length found in women's speech is average. Their sentence consists of subordinate clauses and opens with an adverbial clause. On the contrary, men's speech is elliptic and ungrammatical. Women are emotional and get personal while talking. Men talk facts and are comparatively less emotional. Men's speech contains terms involving quantity and locatives. Women are less judgemental and do not consistently relate to themselves in their utterances (Braun, 2004).

The current study provided some consistencies with previously published work. For example, a study by Alami, Sabbah, and Iranmanesh (2013) using the casual conversations among native English speakers was to compare Lexical Density (LD) of men/women spoken discourse. Where, the results indicated no difference between the discourse of male and female participants in terms of Lexical Density (LD) and discourse length. In other words, the gender of the speaker has no effect on the lexical density of discourse and is almost equally dense. Thus, in the present study also statistically there is no significant difference in discourse parameters of the male and female participants. This proposes that, with respect to the neuro-typical individuals, the gender did not 
have a major relationship with the amount of information given. In general, an individual could express his/her meaning via a short discourse and be sufficiently informative. For example, the male participants talked less on the topic, resulting in lesser number of macro-propositions and total number of words. Whereas, the female participants used lesser transitional elements and relatively reduced total time to complete the narration.

Generally, it is seen that females show advantages in verbal fluency, accuracy, perceptual speed, and fine motor skills whereas males outperform females in spatial, working memory and mathematical abilities (Sherwin, 2003; Zaidi, 2010). The length of discourse samples analysed may be significant in relation to the concept of cognitive distance. That is, the speaker or writer is farther from the topic, as samples become longer. A sample's efficiency and coherence productivity may depend partly on the individual's verbal working memory skills. The more distant the initial topic becomes, more the communicator needs to rely on the initial idea being held in mind as ideas progress (Smith, Heuerman, Wilson, \& Proctor, 2003). Therefore as discourse samples become longer, verbal working memory skills may be an important consideration for male and female participants. Since the female doesn't outperform with respect to working memory abilities, they showed some disadvantages. Where, they completed the narration task with lesser transitional element and reduced total time. Therefore definite instructions should be provided to male and female participants in any discourse analysis task, frequently accompanied with traditional linguistic assessment. This could be one of the practical implications during any discourse analysis. Thus, the present study could be concluded with the (non-statistical/mean) difference between male and female participants are due to working memory. In future direction, this can be proved/disproved in a study on discourse with working memory task with the consideration of increased number of participants and strict control of additional extraneous variable.

\section{Conclusion}

Having a review of background research on coherence analysis indicates that the difference between male/female discourses in terms of productivity and efficiency has not been addressed so far. In order to make the coherence analysis an objective method, we attempted to compare the coherence of male/female participant's verbal discourse, using casual narrations among the non-native English speakers. The results of the study show that male and female discourses are almost equally dense or the results are in concurrence with the previous study on lexical density and discourse length by Alami, Sabbah, and Iranmanesh (2013). Where, the gender of the participants has no effect on the coherence of discourse. The further observation of the raw data indicates that there is relative difference in the number of macro-propositions and the total number of words used during narrative discourse between male and female neuro-typical individuals.

\section{References}

Alami, M., Sabbah, M., \& Iranmanesh, M. (2013). Male-female discourse difference in terms of lexical density. Research Journal of Applied Sciences, Engineering and Technology, 5(23), 5365-5369.

Braun, F. (2004). Talking women differently? Developments and positions in the linguistic gender research [Reden Frauen anders? Entwicklungen und Positionen in der Linguistischen Geschlechterforschung]. In Eichhoff-Cyrus \& Karin (Eds.), Adam, Eve and the language[Adam, Eva und die Sprache] (pp. 9-26). Mannheim: Dudenverlag.

Brizendine, L. (2006). The female brain. New York: Morgan Road/Broadway Books.

Coelho, C., Liles, B., \& Duffy, R. (1991). The use of discourse analyses for the evaluation of higher level traumatically brain injured adults. Brain Injury, 5(4), 381-392. http://dx.doi.org/10.3109/02699059109008111

Coelho, C., Liles, B., \& Duffy, R. (1995). Impairments of discourse abilities and executive functions in traumatically brain-injured adults. Brain Injury, 5(4), 471-477. http://dx.doi.org/10.3109/02699059509008206

Eckert, P., \& McConnell-Ginet, S. (1992). Think practically and look locally: Language and gender as community-based practice. Annual Review of Anthropology, 21, 461-490. 
An investigation of discourse cohesion in Indian male-female causal narration

http://dx.doi.org/10.1146/annurev.an.21.100192.002333

Erman, B. (1987). Pragmatic markers revisited with a focus on you know in adult and adolescent talk. Journal of Pragmatic, 33(9), 1337-1359. http://dx.doi.org/10.1016/S0378-2166(00)00066-7

Goldberg, D. P., \& Williams, P. (1988). A user's guide to the general health questionnaire. Windsor UK: NFER-Nelson.

Halliday, M. A. K., \& Hasan, R. (1976). Cohesion in English. London: Longman.

Halliday, M. A. K., \& Hasan, R. (1985). Language, context, and text: Aspects of language in a social semiotic perspective. Victoria, Canada: Deakin University Press.

Holmes, J. (1995). Women, men and politeness. London and New York: Longman.

Hunt, K. W. (1965). Grammatical structures written at three grade levels. Champaign, IL: National Council of Teachers of English.

Hunt, K. W. (1970). Recent measures in syntactic development. In M. Lester (Ed.), Readings in applied transformation grammar (pp. 179-192). New York: Holt, Rinehert and Winston.

Key, M. R. (1975). Male/female language, with a comprehensive bibliography. Metuchen, NJ: Scarecrow Press.

Lakoff, R. (1975). Language and women's place. Language in Society, 2(1), 45-80. http://dx.doi.org/10.1017/S0047404500000051

Liles, B., Coelho, C., Duffy, R., \& Zalagens, M. (1989). Effects of elicitation procedures on the narratives of normal and closed head-injured adults. Journal of Speech and Hearing Disorders, 54, 356-366. http://dx.doi.org/10.1044/jshd.5403.356

Loban, W. (1976). Language development: Kindergarten through grade twelve. Urbana, IL: National Council of Teachers of English.

Maltz, D. N., \& Broker, R. A. (1982). A cultural approach to male- female miscommunication. In J. Coates (Ed.), Language and gender: A reader (pp. 417-434). Oxford: Blackwell.

Mehl, M. R., Vazire, S., Ramirez-Esparza, N., Slatcher, R. B., \& Pennebaker, J. W. (2007). Are women really more talkative than men? Science, 317(5834), 82. http://dx.doi.org/10.1126/science.1139940

Ostman, J. O. (1983). You know: A discourse functional approach. Amsterdam: John Benjamins.

Razali, N. M., \& Wah, Y. B. (2011). Power comparisons of Shapiro-Wilk, Kolmogorov-Smirnov, Lilliefors and Anderson-Darling tests. Journal of Statistical Modeling and Analytics, 2(1), 21-33.

Shapiro, S. S., \& Wilk, M. B. (1965). An analysis of variance test for normality (Complete samples). Biometrika, 52(3/4), 591-611. http://dx.doi.org/10.1093/biomet/52.3-4.591

Sherwin, B. B. (2003). Estrogen and cognitive functioning in women. Endocrine Reviews, 24(2), $133-151$. http://dx.doi.org/10.1210/er.2001-0016

Smith, R., Heuerman, M., Wilson, B. M., \& Proctor, A. (2003). Analysis of normal discourse patterns. Journal of Brain and Cognition, 53(2), 369-371. http://dx.doi.org/10.1016/s0278-2626(03)00145-3

Venkatesan. S. N. (2009). Readapted from 1997 version NIMH socio economic status scale. Secunderabad: National Institute for the Mentally Handicapped.

West, C., \& Zimmerman, D. H. (1983). Small insults: A study of interruptions in cross-sex conversations between unacquainted persons. In B. Throne, C. Kramarae, \& N. Henley (Eds.), Language, gender and society (pp. 102-117). Cambridge, MA: New Bury House.

West, C., \& Zimmerman, D. H. (1987). Doing gender. Gender Society, 1, 125-151. http://dx.doi.org/10.1177/0891243287001002002

Wilson, B., \& Proctor, A. (2000). Oral and written discourse in adolescents with closed head injury. Brain and Cognition, 41, 325-443.

Wilson, B., Smith, R., \& Proctor, A. (2001). The validity of cognitive distance in oral and written discourse. Brain and Cognition, 46, 304-307. http://dx.doi.org/10.1016/S0278-2626(01)80089-0

Zaidi, Z. F. (2010). Gender differences in human brain: A review. The Open Anatomy Journal, 2, 37-55. http://dx.doi.org/10.2174/1877609401002010037 


\section{Appendix A}

Standard reference for demonstrating differences in the proportion of thematic units within a topic "Profession" for male and female participant during the narration task.

A. The thematic units are:

1. Introduction

2. Type of profession

3. Expansion on the types

4. Describe about their own profession

5. Positives about their profession

6. Negatives about their profession

7. Personal opinion

8. Conclusion

\section{Appendix B}

Example of transcripts demonstrating differences in the proportion of thematic units \{transitional element (in bold and italic) \& macro-proposition (points in numerical) \} within a topic "Profession" from male and female participant during the narration task.

\section{B.1. Twenty year old male verbal narration}

Profession is something which carry out of the education and we, in profession you know to choose a profession we have to master a particular skills. For example- you have to study in that and you have to be very skilled in that work and after that we carry out throughout our life. The professions are nothing but it could be anything even the teaching or design whatever even the farmer also is a profession whose we master we work we work very skillfully. In that particular work and so even our profession like speech language therapy is also profession. The professions are classified based on the people interest like profession is chosen as a people interest and in which they want to do after that and profession can be choice or passion and so if it is a choice then it will be difficult to work. If profession is passion then it is easy to carry out. Then profession to new for example when medical profession and engineering and business like the $\mathrm{n}$ singing, acting and so many professions and those are professions because everyone cannot work in that. So certain people only certain people can work because we should have certain knowledge in that about the work which we are doing and some kind of certificates and it is should be legally qualified that so those are the profession. To conclude we should have a good knowledge about the work which you are doing.

\section{$\underline{\text { Analysis }}$}

1 [Profession is something which carry out of the education and we, in profession you know to choose a profession we have to master a particular skills. For example- you have to study in that and you have to be very skilled in that work and after that we carry out throughout our life.]

2 [The professions are nothing $\boldsymbol{b u t}$ it could be anything even the teaching or design whatever even the farmer also is a profession where we master we work we work very skillfully. In that particular work and so even our profession like speech language therapy is also profession.]

3 [The professions are classified based on the people interest like profession is chosen as a people interest and in which they want to do after that and profession can be choice or passion and so if it is a choice then it will be difficult to work. If profession is passion then it is easy to carry out. ]

$4[$ Then profession to new for example when medical profession and engineering and business like the $\mathrm{n}$ singing, acting and so many professions and those are professions because everyone cannot work in that. So certain people only certain people can work because we should have certain knowledge in that about the work which we are doing and some kind of certificates and it should be legally qualified that so those are the 
profession.]

5 [To conclude we should have a good knowledge about the work which you are doing.]

(Number of transitional element $=12$, Number of Macro-proposition $=5$, Total Number of $w o r d s=246$,

Total time in seconds $=143$ )

\section{B. 2. Twenty year old female participant's verbal narration}

Today I am going to be talking about different jobs and a job is anything that you can do to earn some money. If I have to talk about jobs there are different types of jobs. It can be in construction it can be in auto motors it can be literally anything can be a job. Even working at a cafe at a as a waitress serving somebody food is a job and it has to be respected. We see we often see in India that people classify people categorize them according to the job that they do and I think that is very unfair because every job is equally important. Someone who is sweeping the streets or cleaning the bathrooms does not have a lowly job because of the work that they do. Everybody requires same amount of freedom and the same kind of equality. A doctor is seen to be more respected than the woman who comes to clean your house. But why is that? Both of them offering you a service. Both of them are doing their jobs properly. So both of them deserve the same kind of respect and same kind of equality and they should be treated same everywhere. Of course different job pays differently. That does not mean that they are not human beings because they are not getting paid as somebody else. In the same way we can talk about many jobs which are being overshadowed because of some other job. For example- even my own job as a SLP audiologist many people don't realize importance of this field. They think that a doctor can solve a disordered population. Whereas doctors have almost nothing that they can do. There is no medicine that can cure a communication disorder. It has to be therapeutic intervention. So many don't realize importance of so many jobs like that. And we need to realize the importance of every job and give equality to every person. No matter what their social background or what job that they are doing.

\section{$\underline{\text { Analysis }}$}

1 [Today I am going to be talking about different jobs and a job is anything that you can do to earn some money. If I have to talk about jobs there are different types of jobs. It can be in construction it can be in auto motors it can be literally anything can be a job. Even working at a cafe at a as a waitress serving somebody food is a job and it has to be respected.]

2[We see we often see in India that people classify people categorize them according to the job that they do and I think that is very unfair because every job is equally important. Someone who is sweeping the streets or cleaning the bathrooms does not have a lowly job because of the work that they do. Everybody requires same amount of freedom and the same kind of equality. A doctor is seen to be more respected than the woman who comes to clean your house. But why is that? Both of them offering you a service. Both of them are doing their jobs properly. So both of them deserve the same kind of respect and same kind of equality and they should be treated same everywhere. Of course different job pays differently. That does not mean that they are not human beings because they are not getting paid as somebody else.]

$3[$ In the same way we can talk about many jobs which are being overshadowed because of some other job. For example- even my own job as a SLP audiologist many people don't realize importance of this field. They think that a doctor can solve a disordered population. Whereas doctors have almost nothing that they can do. There is no medicine that can cure a communication disorder. It has to be therapeutic intervention. ]

$4[$ So many don't realize importance of so many jobs like that. And we need to realize the importance of every job and give equality to every person. No matter what their social background or what job that they are doing. ]

(Number of transitional element $=10$, Number of Macro-proposition $=4$, Total Number of words $=341$, Total time in seconds $=130$ ) 
Nagaraj, H., Singh, N., Ponnuchamy, V., \& Thotathil, J. 